\title{
Antitumor effects of curcumin on the proliferation, migration and apoptosis of human colorectal carcinoma HCT-116 cells
}

\author{
LEI XIANG ${ }^{1 *}$, BIN HE ${ }^{1 *}$, QIANG LIU ${ }^{1}$, DONGDONG HU ${ }^{1}$, WENJING LIAO ${ }^{1}$, \\ RUOCHAN LI ${ }^{1}$, XINYI PENG ${ }^{1}$, QIAN WANG ${ }^{2}$ and GANG ZHAO ${ }^{1}$ \\ Departments of ${ }^{1}$ Medical Biology and ${ }^{2}$ Pathogen Biology, School of Basic Medical Sciences, \\ Hubei University of Chinese Medicine, Wuhan, Hubei 430065, P.R. China
}

Received December 6, 2019; Accepted August 13, 2020

DOI: $10.3892 /$ or.2020.7765

\begin{abstract}
Curcumin is the main component of the Chinese herbal plant turmeric, which has been demonstrated to possess antitumor and other pharmacological properties. The aim of the present study was to investigate the effects of curcumin on the viability, migration and apoptosis of human colorectal carcinoma HCT-116 cells, and to explore the underlying molecular mechanisms. In addition, it was investigated whether the antitumor effect of curcumin on HCT-116 cells could match that of the chemotherapeutic drug 5-fluorouracil (5-FU). HCT-116 cells were treated with curcumin (10, 20 and $30 \mu \mathrm{M})$ and 5-FU $(500 \mu \mathrm{M})$, and cell viability and proliferation were detected by Cell Counting Kit- 8 and colony formation assays, respectively. The migration and invasion of treated cells were determined using Transwell and carboxyfluorescein succinimidyl amino ester fluorescent labeling assays. Cell cycle distribution and apoptosis rates were detected by flow cytometry. Furthermore, cell morphology changes associated with apoptosis were observed by fluorescence microscopy with acridine orange/ethidium bromide dual staining. To investigate the possible underlying molecular mechanisms, the gene and protein levels of Fas, Fas-associated via death domain (FADD), caspase-8, caspase-3, matrix metalloproteinase (MMP)-9, nuclear factor (NF)-кB, E-cadherin and claudin-3
\end{abstract}

Correspondence to: Professor Gang Zhao, Department of Medical Biology, School of Basic Medical Sciences, Hubei University of Chinese Medicine, 16 Huangjiahu West Road, Hongshan, Wuhan, Hubei 430065, P.R. China

E-mail: zgcc66@163.com

Dr Qian Wang, Department of Pathogen Biology, School of Basic Medical Sciences, Hubei University of Chinese Medicine, 16 Huangjiahu West Road, Wuhan, Hubei 430065, P.R. China E-mail: elisashop@163.com

*Contributed equally

Key words: curcumin, 5-fluorouracil, colorectal carcinoma, HCT-116 cells, apoptosis, Fas death receptor pathway, nuclear factor- $\kappa \mathrm{B}$, epithelial-to-mesenchymal transition were detected using quantitative PCR analysis, zymography and western blotting. The results revealed that curcumin markedly inhibited the viability and proliferation of HCT-116 cells in a dose- and time-dependent manner. The migration, aggregation and invasion of HCT-116 cells into the lungs of mice were decreased by curcumin treatment in a dose-dependent manner. S-phase arrest and gradually increased apoptotic rates of HCT-116 cells were observed with increasing curcumin concentrations. Additionally, the mRNA and protein levels of apoptosis-associated proteins (Fas, FADD, caspase-8 and caspase-3) and E-cadherin in HCT-116 cells were upregulated following treatment with curcumin in a dose-dependent manner. By contrast, the expression of migration-associated proteins, including MMP-9, NF- $\mathrm{KB}$ and claudin-3, was downregulated with increasing curcumin concentrations. These data suggested that the inhibitory effect of curcumin on HCT-116 cells may match that of 5-FU. Therefore, curcumin induced cell apoptosis and inhibited tumor cell metastasis by regulating the NF- $\mathrm{KB}$ signaling pathway, and its therapeutic effect may be comparable to that of 5-FU.

\section{Introduction}

Colorectal cancer (CRC) is the most common malignant tumor of the digestive system and has the third-highest incidence rate among all cancers (1). CRC has various characteristics, including a fast reproductive rate, exuberant energy metabolism and propensity for invasion (2). Approximately half of all patients are diagnosed during the final stages, and the patients commonly present with metastases to multiple organs, such as the lymph nodes and liver (3). At present, surgical resection and chemotherapy are considered to be the most effective treatment strategies for CRC. However, postoperative invasion and metastasis of CRC may lead to recurrence and even death (4).

Over the past 30 years, 5 -fluorouracil (5-FU) has been the primary chemotherapeutic drug used to treat CRC (5), and it is widely used as first-line chemotherapy for advanced CRC (6). However, $95 \%$ of patients with CRC exhibit resistance to 5-FU, which markedly reduces the cure rate (7). Resistance and associated side effects of chemotherapy remain unsolved problems in the clinical treatment of CRC. Therefore, novel effective low-toxicity anti-CRC drugs from natural antitumor compounds have become an attractive research target. 
Curcumin is a type of polyphenol extracted from the roots of turmeric plants, and it is the main component of turmeric (8). In 1985, Kuttan et al (9) were the first to propose the use of curcumin in the treatment of tumors. Subsequently, a large number of studies $(8,10)$ demonstrated that curcumin may possess anti-infection, anti-inflammatory, antioxidant and tumor growth inhibitory properties. Curcumin has been referred to as a third-generation anticancer drug due to its broad anticancer spectrum, high efficiency and low toxicity (10).

Cell apoptosis, also known as programmed cell death, is an essential process for cells to maintain life activities. Cysteinyl aspartate-specific proteinases (caspases) are a group of proteins that play a key role in promoting apoptosis (11). There are three classical signaling pathways that can induce cancer cell apoptosis: The death receptor, mitochondrial and endoplasmic reticulum signaling pathways (12). Fas receptor-mediated apoptosis is one of the most important death receptor signaling pathways. The cancer stem cell theory of tumor growth suggests that Fas signaling may be involved in cell apoptosis, cell senescence and tumor maintenance (13).

The malignant degree of CRC is determined by hematogenous and lymphatic metastasis, as well as local invasion. The pathogenesis of CRC is currently a clinical research focus. It has been reported that epithelial-to-mesenchymal transition (EMT) is crucial for the development and progression of malignant tumors, mainly manifesting as the disruption of the tight connections between marginal tumor cells (14). Additionally, claudin and matrix metalloproteinase (MMP) protein regulation is associated with tumor metastasis $(15,16)$. The activation of the nuclear factor (NF)- $\mathrm{kB}$ signaling pathway promotes the transcription of inflammatory factors, chemokines, adhesion molecules and growth factor-related genes, thus leading to tumor development (17), and it may represent an effective antitumor strategy for inducing tumor cell apoptosis and inhibiting tumor cell activity and invasion.

The aim of the present study was to investigate the antitumor effects of curcumin on CRC cell proliferation, migration and apoptosis, explore the possible underlying molecular mechanisms, and compare the antitumor efficacy of curcumin with that of 5-FU, in order to determine whether curcumin may be considered as a potential drug for the treatment of patients with CRC.

\section{Materials and methods}

Cells and animals. The HCT-116 cell line was purchased from the China Center for Type Culture Collection. The cells were maintained in RPMI-1640 medium (HyClone; Cytiva) supplemented with 10\% FBS (Hangzhou Sijiqing Biological Engineering Materials Co., Ltd.) and antibiotics (100 U/ml streptomycin and $100 \mathrm{U} / \mathrm{ml}$ penicillin) in an incubator at $37^{\circ} \mathrm{C}$ with 5\% Co2. A total of 24 Kunming mice, aged 4 weeks and weighing $20 \pm 2 \mathrm{~g}$, were purchased from the Hubei Provincial Center for Disease Control and Prevention. The mice were housed at room temperature with $45-55 \%$ humidity and with a 10/14-h light/dark cycle under pathogen-free conditions. The health status of the mice was monitored daily. The humane endpoints were deterioration of their general condition, and the mice were sacrificed in the event of a body weight loss of $>20 \%$. All animal protocols were approved by the
Hubei University of Traditional Chinese Medicine Ethics Committee.

Cell experimental groups. The following five treatment groups were used in the experiments: Control (no curcumin or 5-FU); CUR(L) (10 $\mu \mathrm{M}$ curcumin); CUR(M) (20 $\mu \mathrm{M}$ curcumin); CUR(H) (30 $\mu \mathrm{M}$ curcumin); and 5-FU (500 $\mu \mathrm{M}$ 5-FU) groups. The control and 5-FU groups were used as blank and positive controls, respectively. The 5-FU injection was purchased from Tianjin Jinyao Amino Acid Co., Ltd. Curcumin (Sigma-Aldrich; Merck KGaA) was dissolved in DMSO.

Cell counting Kit-8 (CCK-8) assay. The proliferation ability of HCT-116 cells that were treated with different doses of curcumin and 5-FU for 24,36 and $48 \mathrm{~h}$ was analyzed using a CCK-8 assay. After the HCT-116 cells were seeded in a 96-well culture plate (Wuxi NEST Biotechnology Co., Ltd.) at a density of $5 \times 10^{3}$ cells/well for $24 \mathrm{~h}$, the cells were treated with three doses of curcumin and 5-FU for 24, 36 and $48 \mathrm{~h}$. Subsequently, $10 \mu$ l CCK- 8 dye (Dalian Meilun Biotechnology Co., Ltd.) was added to each well, and the cells were placed in an incubator for $3 \mathrm{~h}$ at $37^{\circ} \mathrm{C}$. Finally, the absorbance was measured at $450 \mathrm{~nm}$ on a microplate reader (Bio-Rad Laboratories, Inc.). The inhibition rate of HCT-116 cell viability with different treatments was calculated according to the following equation: Inhibition rate $(\%)=\left[\right.$ optical density $(\mathrm{OD})_{\text {control group }}-\mathrm{OD}_{\text {treatment }}$ group $/ / \mathrm{OD}_{\text {control group }} \times 100 \%$.

Colony formation assay. Cell viability was detected using a colony formation assay. HCT-116 cells were seeded into a 6-well plate at a density of $3 \times 10^{2}$ cells/well for $24 \mathrm{~h}$, followed by treatment with three different doses of curcumin and 5-FU for $12 \mathrm{~h}$. HCT-116 cells were cultured with new medium for 2 weeks after the drug-containing medium was discarded. The cells were fixed with methanol-glacial acetic acid stationary solution (3:1) at room temperature for $10 \mathrm{~min}$ and stained with Giemsa at room temperature for $15 \mathrm{~min}$. The following formula was used to calculate the colony formation inhibition rate: Colony formation inhibition rate $=($ control group colony number-experimental group colony number)/control group colony number $\times 100 \%$.

Transwell assay. The migration ability of HCT-116 cells was detected using a Transwell assay. Following treatment with curcumin and 5-FU for $12 \mathrm{~h}, \mathrm{HCT}-116$ cells were collected and seeded into the upper chamber of a Transwell plate at a density of $1 \times 10^{5}$ cells in $200 \mu \mathrm{l}$ serum-free medium and incubated for $24 \mathrm{~h}$ at $37^{\circ} \mathrm{C}$. Medium containing $10 \% \mathrm{FBS}(700 \mu \mathrm{l})$ was added to the lower chamber. Subsequently, HCT-116 cells that had migrated to the lower surface of the membrane were fixed in methanol-glacial acetic acid stationary solution (3:1) at room temperature for $10 \mathrm{~min}$ and stained with Giemsa at room temperature for $15 \mathrm{~min}$. The number of migrated cells was counted in four random fields under an inverted microscope (Olympus CK-40; Olympus Corporation) at a magnification of $\mathrm{x} 100$.

Apoptosis assay based on Annexin V-FITC/propidium iodide (PI) flow cytometry. Flow cytometry can distinguish early apoptotic cells, late apoptotic cells and normal cells. The cells were 
seeded in 6-well plates at a density of $1 \times 10^{6}$ cells/well, followed by a $24-\mathrm{h}$ incubation at $37^{\circ} \mathrm{C}$. The cells were then treated with different concentrations of curcumin and 5-FU for 24 and $48 \mathrm{~h}$. The assay was performed using the Annexin V-FITC apoptosis detection kit (BestBio; Nanjing Fengfeng Biological Medicine Technology Co., Ltd.) according to the manufacturer's protocol. Subsequently, the cells were analyzed by flow cytometry (BD Accuri C6; BD Biosciences), and the data were analyzed using FlowJo ${ }^{\mathrm{TM}}$ software (version 10; FlowJo LLC).

Acridine orangelethidium bromide (AO/EB) dual staining assay. Normal, early apoptotic, late apoptotic and necrotic cells may be detected by fluorescence microscopy with green fluorescence. The HCT-116 cells were seeded at a density of $5 \times 10^{5}$ cells/well in 6 -well plates in which a round cover slide was placed, followed by a $24-\mathrm{h}$ incubation at $37^{\circ} \mathrm{C}$. Subsequently, the cells were treated with different concentrations of curcumin and 5-FU for $24 \mathrm{~h}$. The cover slides to which the cells attached were stained with $20 \mu \mathrm{l} \mathrm{AO/EB}$ (Sigma-Aldrich; Merck KGaA) and observed under a green fluorescence microscope (Nikon 80i; Nikon Corporation) at a magnification of $\times 200$. A total of 1,000 cells in each group were counted, and the apoptosis rate was calculated according to the following equation: Apoptosis rate=(early apoptotic cells + late apoptotic cells)/1,000 x100\%.

Cell cycle assay based on flow cytometry. The HCT-116 cell culture, drug treatment and cell collection methods were as described for the apoptosis assay based on Annexin V-FITC/PI flow cytometry. The cells were fixed and incubated with $400 \mu \mathrm{l}$ PI dye solution and $100 \mu \mathrm{l}$ RNase $(100 \mu \mathrm{g} / \mathrm{ml})$ at $4^{\circ} \mathrm{C}$ for $30 \mathrm{~min}$. The cells were filtered using a 300 mesh $(70 \mu \mathrm{m})$ cell strainer and analyzed by flow cytometry. The experimental results were analyzed using Modfit LT software (version 3.1; Verity Software House).

Zymography assay. MMP-9 expression in HCT-116 cells was analyzed using a zymography assay. Following drug treatment for $12 \mathrm{~h}$, the medicated medium was discarded, and the cells were washed twice with PBS. Subsequently, the cells were cultured with serum-free medium for another $24 \mathrm{~h}$. The medium was harvested, and a 20- $\mu \mathrm{l}$ medium sample was analyzed in a zymography assay. The zymography assay was performed as previously described (18). The results were obtained using a gel imaging system (ChemiDoc XRS ${ }^{+}$; Bio-Rad Laboratories, Inc.).

Colon cancer cell metastasis in mouse lung samples. Following curcumin and 5-FU treatment for $12 \mathrm{~h}, \mathrm{HCT}-116$ cells were collected and washed with PBS. The cells were suspended in PBS to a density of $4 \times 10^{6} / \mathrm{ml}$. The cancer cells were then labeled with $5 \mu \mathrm{M}$ carboxyfluorescein succinimidyl amino ester (CFSE) in a $37^{\circ} \mathrm{C}$ incubator for $10 \mathrm{~min}$. After washing with serum-free medium and PBS, the cancer cells were again suspended in PBS to a density of $2.5 \times 10^{6} / \mathrm{ml}$. The 4-week-old Kunming mice were divided into three groups $(n=8$ per


via the tail vein. At 6 and $24 \mathrm{~h}$ after injection, the 24 mice were anesthetized by intraperitoneal injection of $10 \%$ chloral hydrate (300 mg/kg body weight) and immediately sacrificed by cervical dislocation. The lungs were then harvested, dissected and fixed with $4 \%$ paraformaldehyde for $6 \mathrm{~h}$ at $4{ }^{\circ} \mathrm{C}$. Subsequently, the mouse lung samples were dehydrated in $20 \%$ sucrose. Frozen mouse lung sections were observed under a fluorescence microscope (Nikon 80i; Nikon Corporation; magnification, $\mathrm{x} 100$ ) at $488 \mathrm{~nm}$. Additionally, 20 fields of view of lung tissue sections were randomly selected, and the number of fluorescent nodules observed in each section was counted (19).

Reverse transcription-quantitative PCR (RT-qPCR) analysis. Total RNA was extracted from HCT-116 cells treated with curcumin $(20 \mu \mathrm{M})$ and 5 -FU $(500 \mu \mathrm{M})$ for $24 \mathrm{~h}$ using TRIzol ${ }^{\circledR}$ reagent (Thermo Fisher Scientific, Inc.). cDNA was synthesized from $1 \mu \mathrm{g}$ RNA using the Bestar ${ }^{\mathrm{TM}}$ qPCR RT kit (DBI ${ }^{\circledR}$ Bioscience). mRNA expression levels were assessed with a qPCR assay using SYBR Green Realtime PCR Master mix on a Bio-Rad CFX96 Real-Time PCR system (Bio-Rad Laboratories, Inc.). The assay was performed according to the manufacturer's protocol. The housekeeping gene used for normalization was $\beta$-actin. The primers (Tsinke Biological Technology Co., Ltd.) used were as follows: Fas forward, 5'-TCTGGTTCTTACGTCTGTTGC-3' and reverse, 5'-CTG TGCAGTCCCTAGCTTTCC-3'; Fas-associated via death domain (FADD) forward, 5'-GGGAGTCACTGAGAATCT GGAA-3' and reverse, 5'-GGCCTGCTGAACCTCTTG TAC-3'; caspase-8 forward, 5'-TTTCTGCCTACAGGGTCA TGC-3' and reverse, 5'-GCTGCTTCTCTCTTTGCTGAA-3'; caspase-3 forward, 5'-CATGGAAGCGAATCAATGGAC T-3' and reverse, 5'-CTGTACCAGACCGAGATGTCA-3'; and $\beta$-actin forward, 5'-TGCTGTCCCTGTATGCCTCT-3' and reverse, 5'-TTTGATGTCACGCACGATTT-3'. The following thermocycling conditions were used: $95^{\circ} \mathrm{C}$ for $60 \mathrm{sec}$, followed by 40 cycles of $95^{\circ} \mathrm{C}$ for $15 \mathrm{sec}$ and $60^{\circ} \mathrm{C}$ for $60 \mathrm{sec}$. Relative mRNA expression levels were determined using the $2^{-\Delta \Delta \mathrm{Cq}}$ method (2). The experiments were performed with four repeats for each sample.

Western blotting. The effects of curcumin and 5-FU on the expression levels of Fas, FADD, caspase-8, caspase-3, NF- $\kappa$ B, E-cadherin and claudin-3 were analyzed using western blotting. Protein samples were obtained from HCT-116 cells that were treated with different concentrations of curcumin and 5-FU for $24 \mathrm{~h}$ using cell lysis buffer (Wuhan Servicebio Biotechnology Co., Ltd.). The protein concentration was detected using the BCA method (Beyotime Biotechnology Co., Ltd.). Total protein $(20 \mu \mathrm{g})$ was separated using SDS-PAGE (12\% gel) and transferred onto a nitrocellulose membrane (Millipore; Merck KGaA). Following blocking with Tris-buffered saline containing 1\% Tween-20 and 5\% fat-free milk powder, the membrane was incubated with the corresponding antibodies. The assay protocol has been previously described in detail (2). The following antibodies were used: CD95/Fas (cat. no. bs-0215R; rabbit polyclonal; 1:1,000 dilution; Beijing Biosynthesis Biotechnology Co., Ltd.), FADD (cat. no. SC-271520; mouse polyclonal; 1:1,000 dilution; Santa Cruz Biotechnology, Inc.), caspase-8 (cat. no. bsm33190M; rabbit polyclonal; 1:1,000 dilution; Beijing Biosynthesis Biotechnology Co., Ltd.), cleaved caspase-8 (cat. no. Asp384; mouse polyclonal; 1:1,000 dilution; Cell Signaling Technology, 
Inc.), caspase-3 (cat. no. BS1067; rabbit polyclonal; 1:1,000 dilution; Santa Cruz Biotechnology, Inc.), cleaved caspase-3 (cat. no. Asp175; rabbit polyclonal; 1:1,000 dilution; Cell Signaling Technology, Inc.), NF-кB (cat. no. bs-19789R; rabbit polyclonal; 1:1,000 dilution; Beijing Biosynthesis Biotechnology Co., Ltd.), E-cadherin (cat. no. 3195S; rabbit polyclonal; 1:1,000 dilution; Cell Signaling Technology, Inc.), claudin-3 (cat. no. 3195S; rabbit polyclonal; 1:1,000 dilution; Bioworld Technology, Inc.), $\beta$-actin (cat. no. SC-47778; mouse polyclonal; 1:1,000 dilution; Santa Cruz Biotechnology, Inc.) and horseradish peroxidase immunoglobulin $\mathrm{G}$ antibody (cat. no. SE134, goat anti-rabbit, 1:1,000 dilution; and cat. no. SESE131, goat anti-mouse, 1:1,000 dilution; Beijing Solarbio Science \& Technology Co., Ltd.). Human $\beta$-actin was used for normalization. Following incubation with secondary antibody and chemiluminescence reagent (Wuhan Servicebio Biotechnology Co., Ltd.), the blots of the proteins of interest were scanned using a gel imaging system (ChemiDoc XRS+; Bio-Rad Laboratories, Inc.) and the analysis was performed using Image $\mathrm{Lab}^{\mathrm{TM}}$ software (version 5.0; MCM DESIGN). The relative protein expression levels were calculated as follows: Relative expression of protein $=$ (gray value of the band in the experimental group)/(gray value of the band in the control group).

Statistical analysis. All experiments were repeated three times. Data were analyzed using GraphPad Prism software (version 6.0; GraphPad Software, Inc.). Student's t-test and ANOVA followed by Tukey's post hoc test were used to compare different groups. $\mathrm{P}<0.05$ was considered to indicate a statistically significant difference. Data are presented as the mean \pm standard deviation $(n=3)$.

\section{Results}

Curcumin inhibits the proliferation and viability of HCT-116 cells. The results of the CCK- 8 assay revealed that the proliferation of cells in the curcumin and 5-FU groups differed compared with that in the blank control group (Fig. 1A). The inhibitory effect increased gradually with increasing curcumin concentration in a dose- and time-dependent manner $(\mathrm{P}<0.05)$. The cell proliferation inhibition rates of the CUR $(\mathrm{H})$ group at 24, 36 and $48 \mathrm{~h}$ were not significantly different from those of the 5-FU group. Additionally, according to the colony formation assay results (Fig. 1B and C), the cell viability in each group was significantly inhibited compared with the blank control group $(\mathrm{P}<0.05)$, and the inhibition rate of CUR(H) $(49.4 \pm 3.15 \%)$ was higher compared with that of 5-FU $(48.8 \pm 2.50 \%)$. These data indicated that curcumin inhibited the viability and proliferation of HCT-116 cells, and its effect was comparable to that of 5-FU.

Curcumin inhibits migration and MMP-9 expression in HCT-116 cells. The results of the Transwell assay (Fig. 2A) revealed that numerous cells in the control group migrated into the membrane of the upper chamber, whereas curcumin treatment markedly reduced the cell migration rate (Fig. 2B). Notably, the inhibitory effect on migration increased gradually with increasing curcumin concentration in a dose-dependent manner $(\mathrm{P}<0.05)$. The inhibition rate in the Transwell assays was markedly increased from that of the control group to $44.64 \pm 2.60 \%$ in the CUR(L), 61.59 $\pm 2.13 \%$ in the CUR(M), $86.53 \pm 0.72 \%$ in the CUR $(\mathrm{H})$ and $70.15 \pm 7.04 \%$ in the $5-\mathrm{FU}$ treatment groups. Furthermore, the zymography assay demonstrated that curcumin treatment decreased MMP-9 expression in HCT-116 cells (Fig. 2C and D). Overall, the data demonstrated that curcumin markedly inhibited the migration of HCT-116 cells. Notably, the inhibition of migration and MMP-9 expression in HCT-116 cells following curcumin treatment reached the levels observed with 5-FU treatment.

Curcumin induces apoptosis of HCT-116 cells. As shown in Fig. 3A and B, early and late apoptotic cells may be selected by flow cytometry. The apoptosis rate of each group was significantly different from that of the blank control group $(\mathrm{P}<0.05$; Fig. 3C). The proportion of apoptotic cells increased from $3.6 \pm 0.60 \%$ in the control group to $23.7 \pm 1.01 \%$ in the CUR(L), $27.2 \pm 2.00 \%$ in the CUR(M), 34.6 $\pm 3.00 \%$ in the CUR(H) and $34.9 \pm 3.01 \%$ in the $5-\mathrm{FU}$ experimental groups following treatment for $24 \mathrm{~h}$. The proportion of apoptotic cells increased from $22.07 \pm 2.00 \%$ in the control group to $37.08 \pm 2.51 \%$ in the CUR(L), $58.80 \pm 2.01 \%$ in the CUR(M), $89.20 \pm 2.03 \%$ in the CUR(H) and $90.02 \pm 4.51 \%$ in the 5-FU experimental groups following treatment for $48 \mathrm{~h}$. At 24 and $48 \mathrm{~h}$, the apoptosis rate of the CUR $(\mathrm{H})$ group was not significantly different from that of the 5-FU group. Therefore, curcumin induced apoptosis of the HCT-116 cells in a dose- and time-dependent manner $(\mathrm{P}<0.05)$, and the ability of curcumin to induce the apoptosis of HCT-116 cells was comparable to that of 5-FU.

Curcumin induces morphological changes in HCT-116 cells. Following staining with $\mathrm{AO} / \mathrm{EB}$, normal cells emitted green or yellow-green fluorescence, early apoptotic cells emitted orange fluorescence, and late apoptotic cells emitted red fluorescence, with nuclear debris and apoptotic bodies. As shown in Fig. 3D, the morphology of cells in each group was markedly altered. The HCT-116 cells became smaller and more rounded following curcumin and 5-FU treatment compared with cells in the control group. Not only did the cell density decrease with the increase in drug concentration, but the proportion of early and late apoptotic cells also increased gradually. The apoptosis rates were as follows: Control, $4.30 \pm 0.86 \%$; CUR(L), 23.576 $\pm 1.01 \%$; CUR(M), 33.16 $\pm 1.02 \%$; CUR(H), $43.2 \pm 1.08 \%$; and $5-\mathrm{FU}, 43.1 \pm 0.95 \%$. The apoptosis rate of each group was significantly different from that of the blank control group $(\mathrm{P}<0.05)$, and the apoptosis rate of the CUR $(\mathrm{H})$ group was not significantly different from that of the 5-FU group (Fig. 3E). Curcumin induced apoptosis in the HCT-116 cells in a dose-dependent manner $(\mathrm{P}<0.05)$. The percentages of early and late apoptotic cells increased gradually with an increase in drug concentration. These results were consistent with the flow cytometry results, in that curcumin induced apoptosis of HCT-116 cells, and its effect was comparable to that of 5-FU treatment.

Curcumin induces S-phase arrest in HCT-116 cells. As shown in Fig. 4A, the proportion of cells that were arrested in the S-phase in each experimental group was significantly different from that in the blank control group $(\mathrm{P}<0.05)$, and this proportion increased in a dose-dependent manner 



Figure 1. Curcumin inhibits the proliferation and viability of HCT-116 cells. (A) HCT-116 cells were treated with three different doses of curcumin (10, 20 and $30 \mu \mathrm{M})$ and 5-FU $(500 \mu \mathrm{M})$ for 24, 36 and $48 \mathrm{~h}$. Cell proliferation was determined using Cell Counting Kit-8 assays. (B) Effects of curcumin and 5-FU on the viability of HCT-116 cells according to a colony formation assay. (C) Quantification of the inhibitory rate in the colony formation assay. Results are presented as the mean \pm standard error of the mean $(\mathrm{n} \geq 3)$. ${ }^{*} \mathrm{P}<0.05$ and ${ }^{* *} \mathrm{P}<0.01$ vs. control group. 5-FU, 5-fluorouracil; CUR(L), $10 \mu \mathrm{M}$ curcumin; CUR(M), $20 \mu \mathrm{M}$ curcumin; CUR(H), $30 \mu \mathrm{M}$ curcumin; NS, not significant.

( $\mathrm{P}<0.05$; Fig. 4B). The proportions of cells that were arrested in the $G_{0} / G_{1}$ and $G_{2} / M$ phase were lower compared with those in the blank control group. The proportion of cells in S-phase increased from $17 \pm 0.60 \%$ in the control group to $23 \pm 0.81 \%$ in the CUR(L), $26.4 \pm 1.00 \%$ in the CUR(M), $45.83 \pm 0.40 \%$ in the $\mathrm{CUR}(\mathrm{H})$ and $42.8 \pm 3.00 \%$ in the $5-\mathrm{FU}$ treatment groups. These data indicated that curcumin induced $\mathrm{S}$-phase arrest in HCT-116 cells, and this effect reached the level of 5-FU treatment.

Curcumin inhibits HCT-116 cell metastasis to mouse lungs. Tumor cells migrate through the blood to the lungs, where they accumulate by penetrating through the wall of the vessels. HCT-116 cells were fluorescence-labeled with CFSE and were injected into the mice via the tail vein. When the lungs were surgically removed from the mice, the ability of cells to aggregate and invade into the lungs were evaluated by counting the number of fluorescent nodules in the lungs. At $6 \mathrm{~h}$ after HCT-116 cells were injected (Fig. 4C), the numbers of cancer cells that had invaded the lungs of the treatment groups $(20 \mu \mathrm{M}$ curcumin and $500 \mu \mathrm{M} 5$-FU) were markedly decreased compared with those in the control group. As shown in Fig. 4D, the number of fluorescent nodules decreased from $255 \pm 2 \%$ in the control group to $150 \pm 2 \%$ (CUR $20 \mu \mathrm{M}$ ) and $160 \pm 2 \%(5-\mathrm{FU})$ in the experimental groups. At $24 \mathrm{~h}$ after injection, the body's immune system quickly cleared a large number of HCT-116 cells (Fig. 4C and D), and the numbers of HCT-116 cells in lung tissue samples from each group were reduced compared with those at $6 \mathrm{~h}$. Only a small percentage of HCT-116 cells invaded the lung tissue, and their behavior determined the number of metastases. These data indicated that curcumin inhibited CRC cell metastasis in vivo.

Curcumin affects the expression levels of the Fas death receptor pathway-associated genes. The present study aimed to explore the possible molecular mechanisms of apoptosis through western blot analysis. Compared with the blank control group, the expression levels of Fas, FADD, caspase-8 and caspase-3 were found to be significantly upregulated $(\mathrm{P}<0.05)$ following curcumin $(20 \mu \mathrm{M})$ and 5-FU $(500 \mu \mathrm{M})$ treatment for $24 \mathrm{~h}$ (Fig. 5A).

Curcumin affects the expression levels of Fas death receptor pathway-associated proteins and tumor metastasis-associated proteins. Compared with the blank control group, the expression levels of Fas, FADD, cleaved caspase- 8 and cleaved caspase-3 in each drug treatment group were significantly upregulated $(\mathrm{P}<0.05)$. As shown in Fig. $5 \mathrm{~B}$ and $\mathrm{C}$, the expression levels of Fas, FADD, cleaved caspase- 8 and cleaved caspase- 3 increased gradually with increasing curcumin 

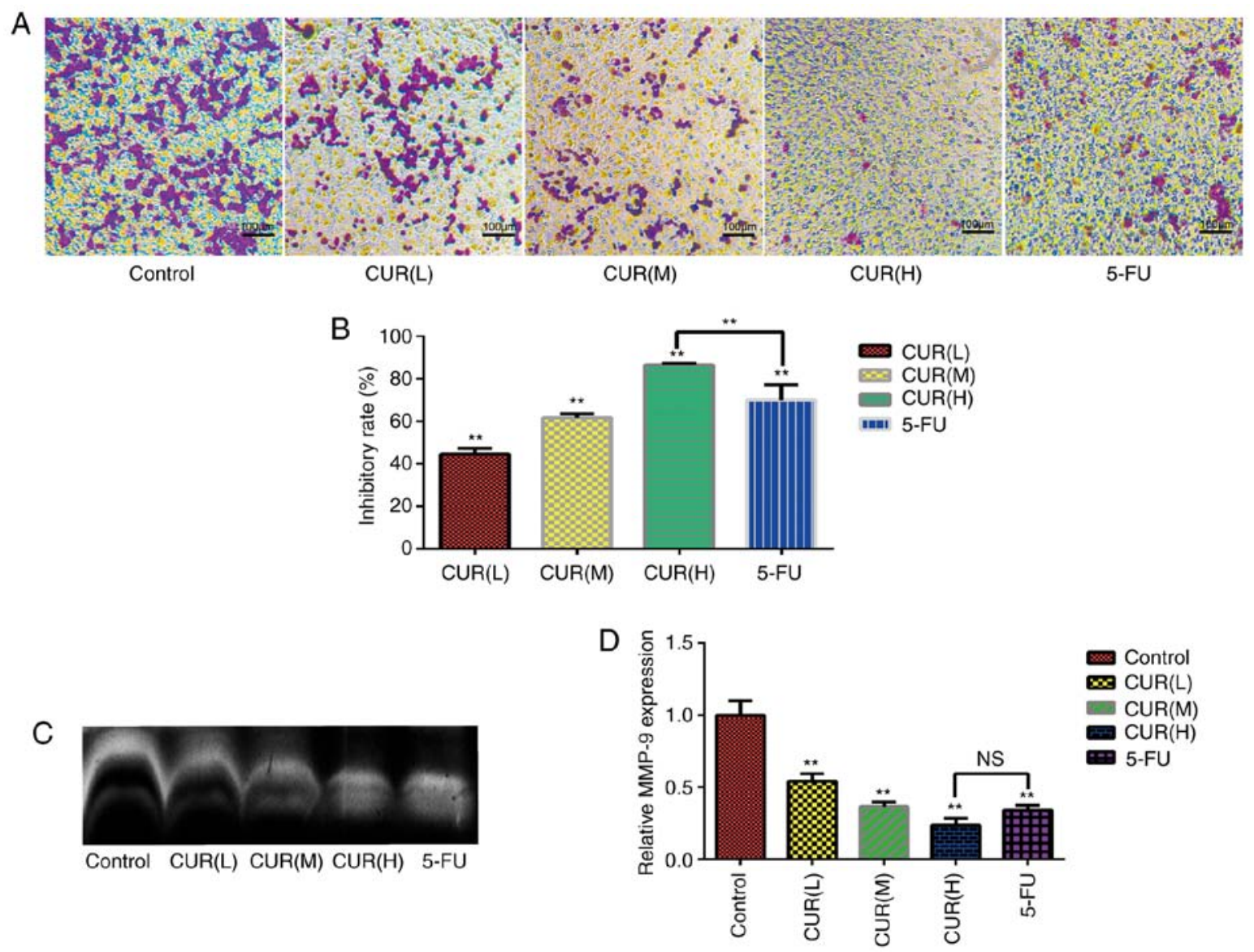

Figure 2. Curcumin inhibits migration and MMP-9 expression in HCT-116 cells. (A) Effect of curcumin and 5-FU on the migratory ability of HCT-116 cells in a Transwell assay. (B) Quantification of the inhibitory rate in the Transwell assay. (C) MMP-9 expression was detected using a zymography assay. (D) Semi-quantification of MM9-P expression as detected using a zymography assay. Results are presented as the mean \pm standard error of the mean ( $\mathrm{n} \geq 3$ ). ${ }^{* *} \mathrm{P}<0.01$ vs. control group. 5-FU, 5-fluorouracil; CUR(L), $10 \mu \mathrm{M}$ curcumin; CUR(M), $20 \mu \mathrm{M}$ curcumin; CUR(H), $30 \mu \mathrm{M}$ curcumin; MMP-9, matrix metalloproteinase 9; NS, not significant.

concentrations $(\mathrm{P}<0.05)$. These data indicated that curcumin promoted the activation of the Fas death receptor signaling pathway to induce apoptosis in HCT-116 cells. Additionally, the relative protein expression levels of NF- $\kappa \mathrm{B}$ and claudin-3 decreased gradually with increasing curcumin concentrations (Fig. 5B and C). Conversely, curcumin treatment upregulated the relative expression levels of E-cadherin. These data indicated that curcumin treatment not only regulated the apoptosis, but also the metastasis of CRC cells. Notably, the relative expression levels of these proteins in the CUR $(\mathrm{H})$ group were significantly different from those in the 5-FU group $(\mathrm{P}<0.05)$. The data indicated that the regulatory effect of curcumin on the Fas death receptor signaling pathway and metastasis of HCT-116 cells could match or even exceed that of 5-FU treatment.

\section{Discussion}

The treatment options for CRC include surgery, radiotherapy, and a combination of chemotherapy and targeted therapy, as well as expensive cytotoxic drugs with various non-therapeutic effects. Although there have been advances in the treatment of $\mathrm{CRC}$, the recurrence and mortality rates of CRC remain high (20). 5-FU has a wide antitumor spectrum and may be used in the treatment of digestive tract malignant tumors, as well as breast, ovarian, lung, cervical, bladder and skin cancer. In recent years, numerous studies have investigated the molecular mechanism of action of 5-FU in tumors, and a number of potential molecular mechanisms have been implicated in its effects. However, 5-FU inhibits bone marrow hematopoiesis and reduces the secretion of cytokines, such as interleukin-2, interferon- $\gamma$ and tumor necrosis factor- $\alpha$ (21). Furthermore, it has been demonstrated that the effective concentration range of 5-FU is narrow, and a high blood concentration is likely to cause treatment-related side effects, whereas a low blood concentration will not achieve the desired chemotherapeutic efficacy in the treatment of CRC (22).

Curcumin, a naturally occurring phytotherapeutic agent, has demonstrated therapeutic efficacy in the treatment of cancer, and it has attracted attention as an antitumor agent against gastric cancer, liver cancer and CRC (23). Curcumin may be combined with or replace other chemotherapeutic drugs, such as 5-FU, in oncotherapy $(24,25)$. Studying these molecular targets also offers the possibility of developing novel drugs to replace 5-FU in treatment. The safety of curcumin has been studied in animals, healthy individuals and patients $(26,27)$, and curcumin is generally recognized as a safe substance. In cell culture studies, normal cell proliferation and viability may be affected by curcumin, and they would be reduced at certain concentrations. 



Control
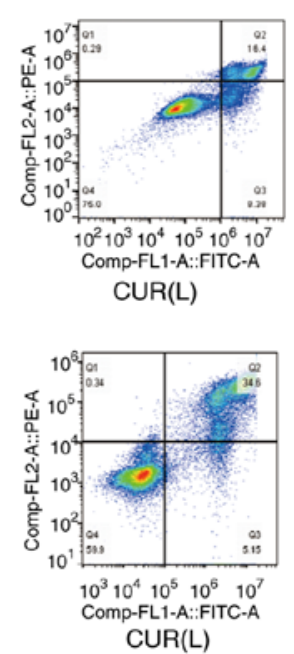

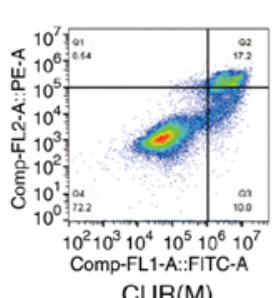

CUR(M)

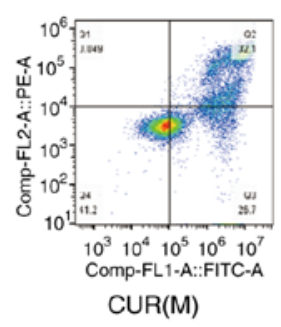

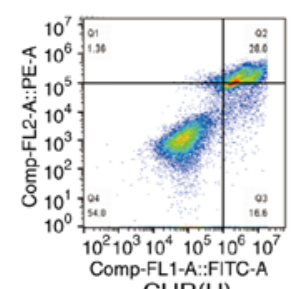

CUR(H)

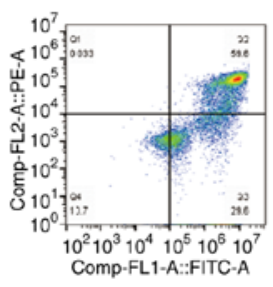

CUR(H)
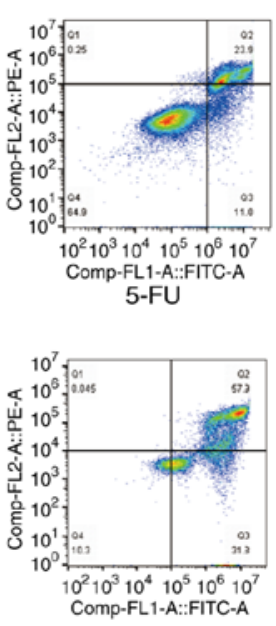

$5-\mathrm{FU}$



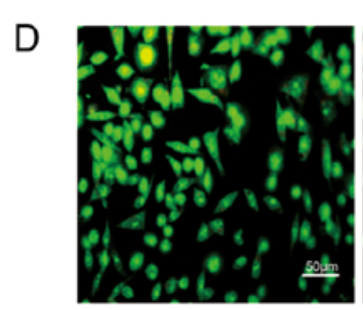

Control

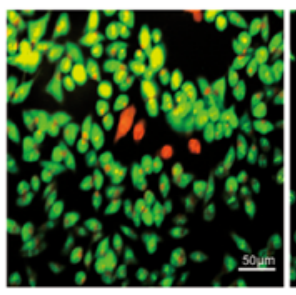

CUR(L)

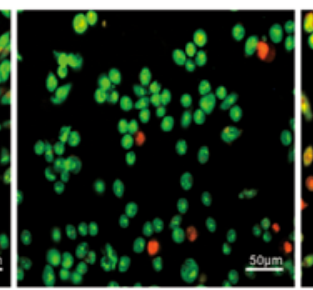

CUR(M)

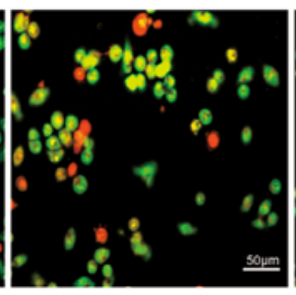

$\operatorname{CUR}(\mathrm{H})$

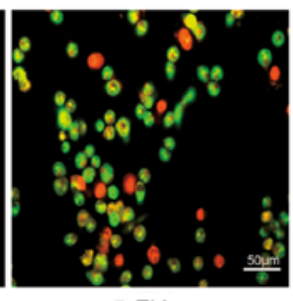

5-FU

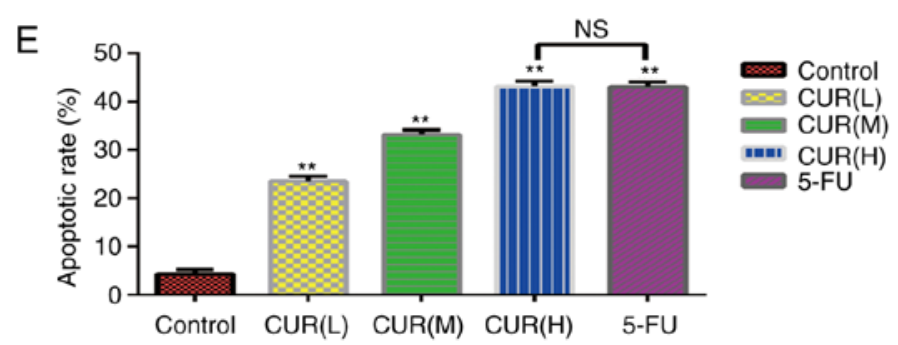

Figure 3. Curcumin induces apoptosis of HCT-116 cells. (A and B) Following treatment with three different doses of curcumin (10, 20 and $30 \mu \mathrm{M}$ ) and 5-FU $(500 \mu \mathrm{M})$ for 24 and $48 \mathrm{~h}$, the apoptosis rate of HCT-116 cells was determined using Annexin V-FITC/PI dual-staining flow cytometry. (C) Quantification of the apoptosis rate in HCT-116 cells detected by Annexin V-FITC/PI dual-staining flow cytometry. (D) Morphological alterations in HCT-116 cells treated with three different concentrations of curcumin for $24 \mathrm{~h}$, as observed using fluorescence microscopy with AO/EB staining. (E) Quantification of the results of the $\mathrm{AO} / \mathrm{EB}$ dual-staining assay. Results are presented as the mean \pm standard error of the mean (n $\geq 3)$. ${ }^{* *} \mathrm{P}<0.01$ vs. control group. 5-FU, 5-fluorouracil; AO/EB, acridine orange/ethidium bromide; CUR(L), $10 \mu \mathrm{M}$ curcumin; CUR(M), $20 \mu \mathrm{M}$ curcumin; CUR(H), $30 \mu \mathrm{M}$ curcumin; NS, not significant; PI, propidium iodide.

However, curcumin was more cytotoxic against cancer cells rather than normal cells, which indicated the potential of curcumin as an antitumor agent (28). Therefore, experiments were performed on the basis that curcumin is non-toxic or low-toxic.

The main antitumor mechanisms of curcumin that have been described thus far are as follows: Inhibition of proliferation by blocking the cell cycle (29), regulation of signaling pathways inhibiting proliferation (30), and inhibition of tumor metastasis (31). Pro-apoptotic proteins, such as Bcl-2 and Bax, induce cell apoptosis (32). In addition, activation of the tumor suppressor gene p53 (33), and inhibition of EMT, MMP, $\mathrm{NF}-\kappa \mathrm{B}$ and angiogenesis (34-36), can regulate tumor cell invasion and metastasis. However, to the best of our knowledge, the anticancer effect of curcumin in CRC cells based on the death receptor signaling pathway has rarely been reported to date. The purpose of the present study was to determine the effects of curcumin on the proliferation, migration and apoptosis of 

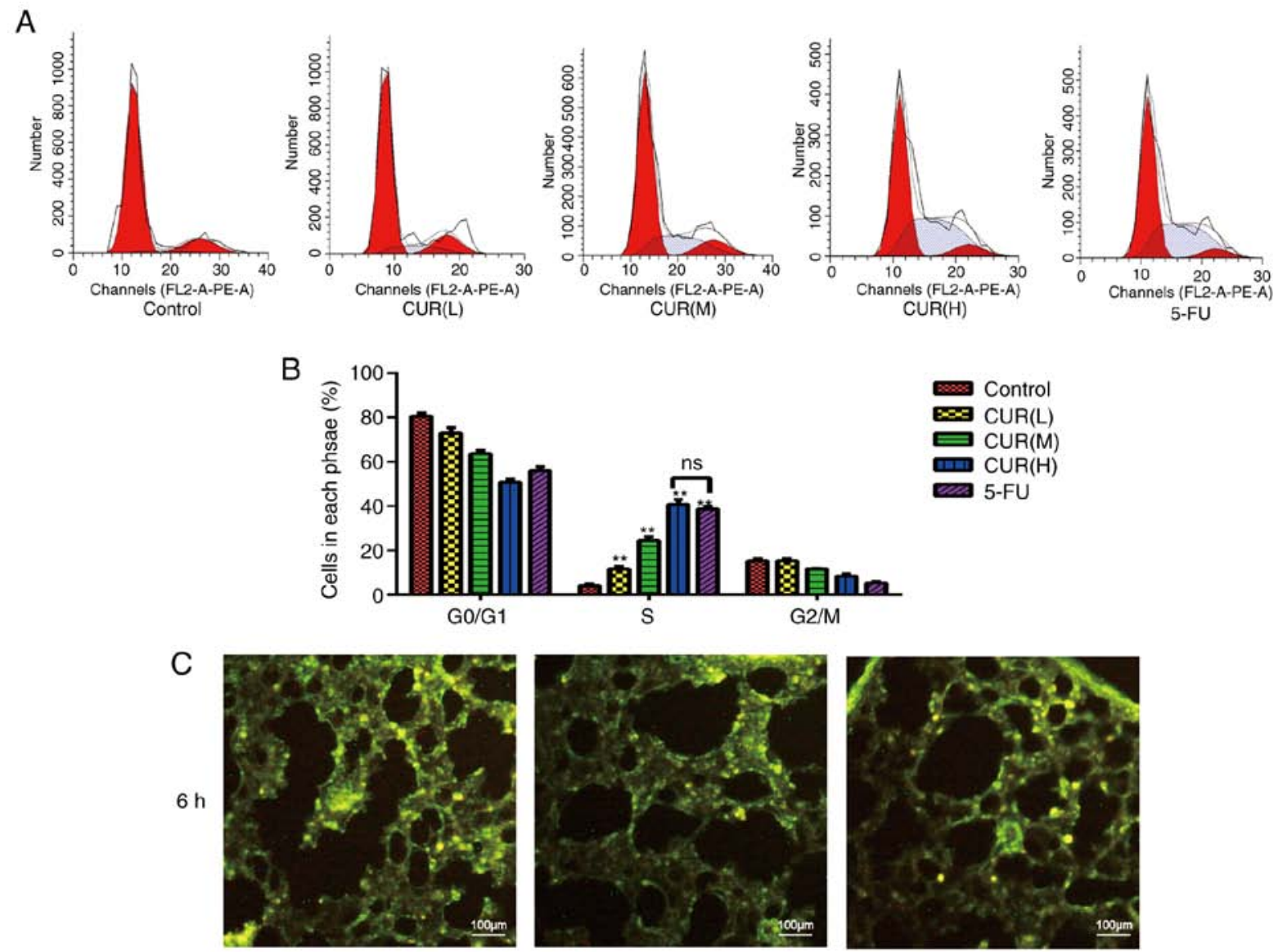

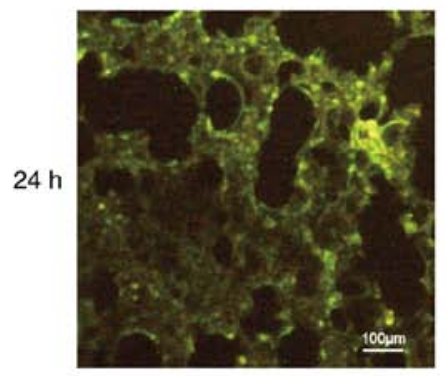

Control

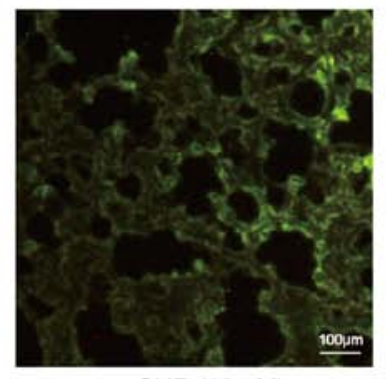

CUR $(20 \mu \mathrm{M})$

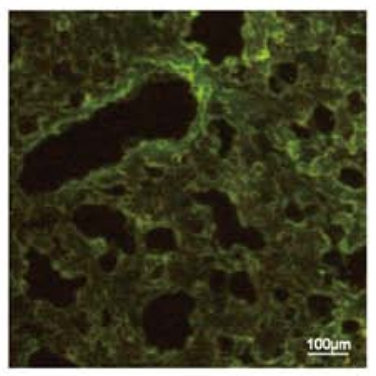

$5-\mathrm{FU}(500 \mu \mathrm{M})$

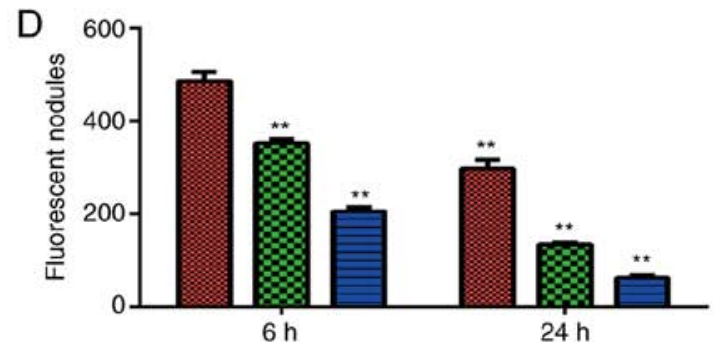

Figure 4. Curcumin induces S-phase arrest in HCT-116 cells and inhibits HCT-116 cell metastasis into the lungs of mice. (A) Cell cycle distribution changes in HCT-116 cells induced by curcumin $(10,20$ and $30 \mu \mathrm{M})$ and 5-FU $(500 \mu \mathrm{M})$ treatment. The effect was assessed using propidium iodide staining flow cytometry. (B) Quantification of the cell cycle distribution of HCT-116 cells. (C) Following treatment with curcumin (20 $\mu \mathrm{M})$ and 5-FU (500 $\mu \mathrm{M})$, HCT-116 cells labeled with CFSE aggregated and invaded into mouse lungs via the blood circulation. (D) Quantification of the number of fluorescent nodules in mouse lung tissues at 6 and $24 \mathrm{~h}$. Results are presented as the mean \pm standard error of the mean $(\mathrm{n} \geq 3) .{ }^{* *} \mathrm{P}<0.01$ vs. control group. 5-FU, 5-fluorouracil; CUR(L), $10 \mu \mathrm{M}$ curcumin; CUR(M), $20 \mu \mathrm{M}$ curcumin; CUR(H), $30 \mu \mathrm{M}$ curcumin; NS, not significant. CFSE, carboxyfluorescein succinimidyl amino ester.

HCT-116 cells. Additionally, the possible molecular mechanisms through which curcumin inhibits HCT-116 cell apoptosis and migration were investigated. Furthermore, the inhibitory effect of curcumin on HCT-116 cells was compared to that of 5-FU.
The results of the CCK-8 and colony formation assays revealed that curcumin exerted an inhibitory effect on cell viability and proliferation in a dose- and time-dependent manner. The results were consistent with the hypothesis of Aaron et al (37) and Shakibaei et al (32), who hypothesized that 


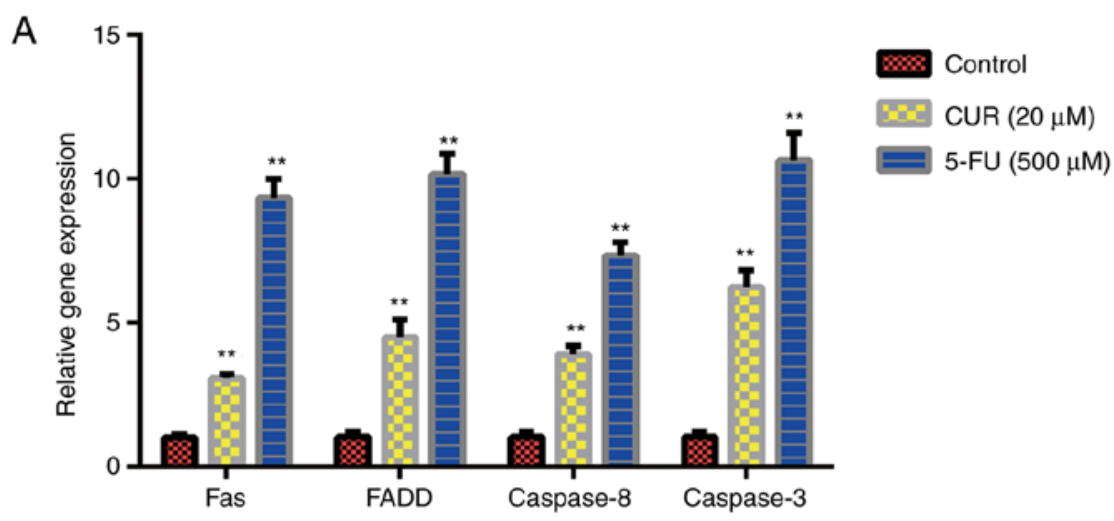

B

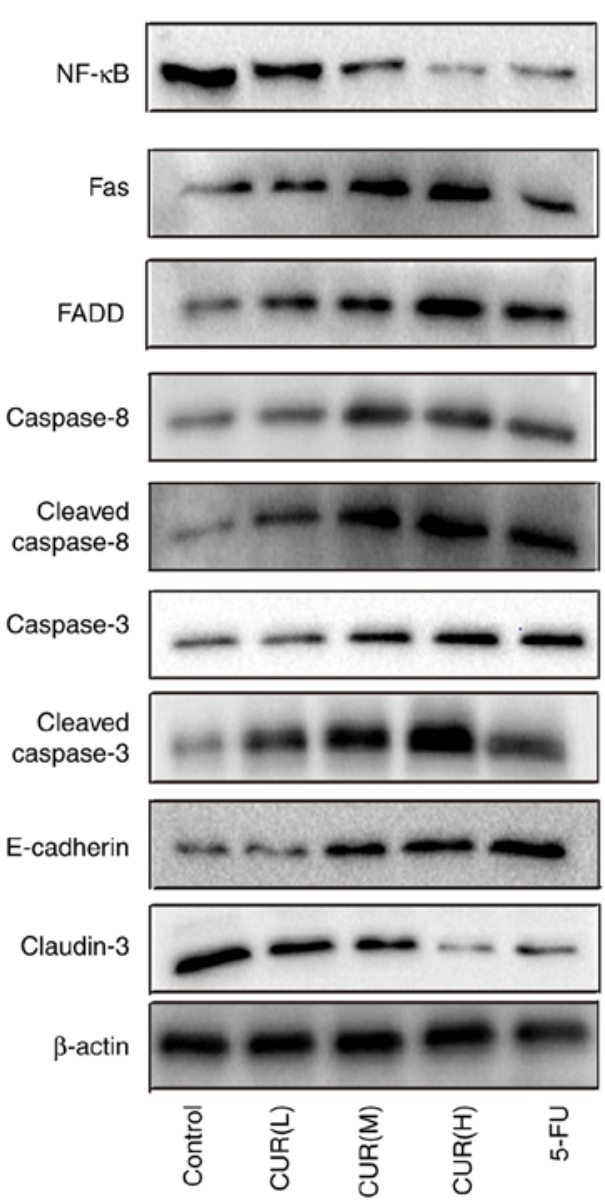

C
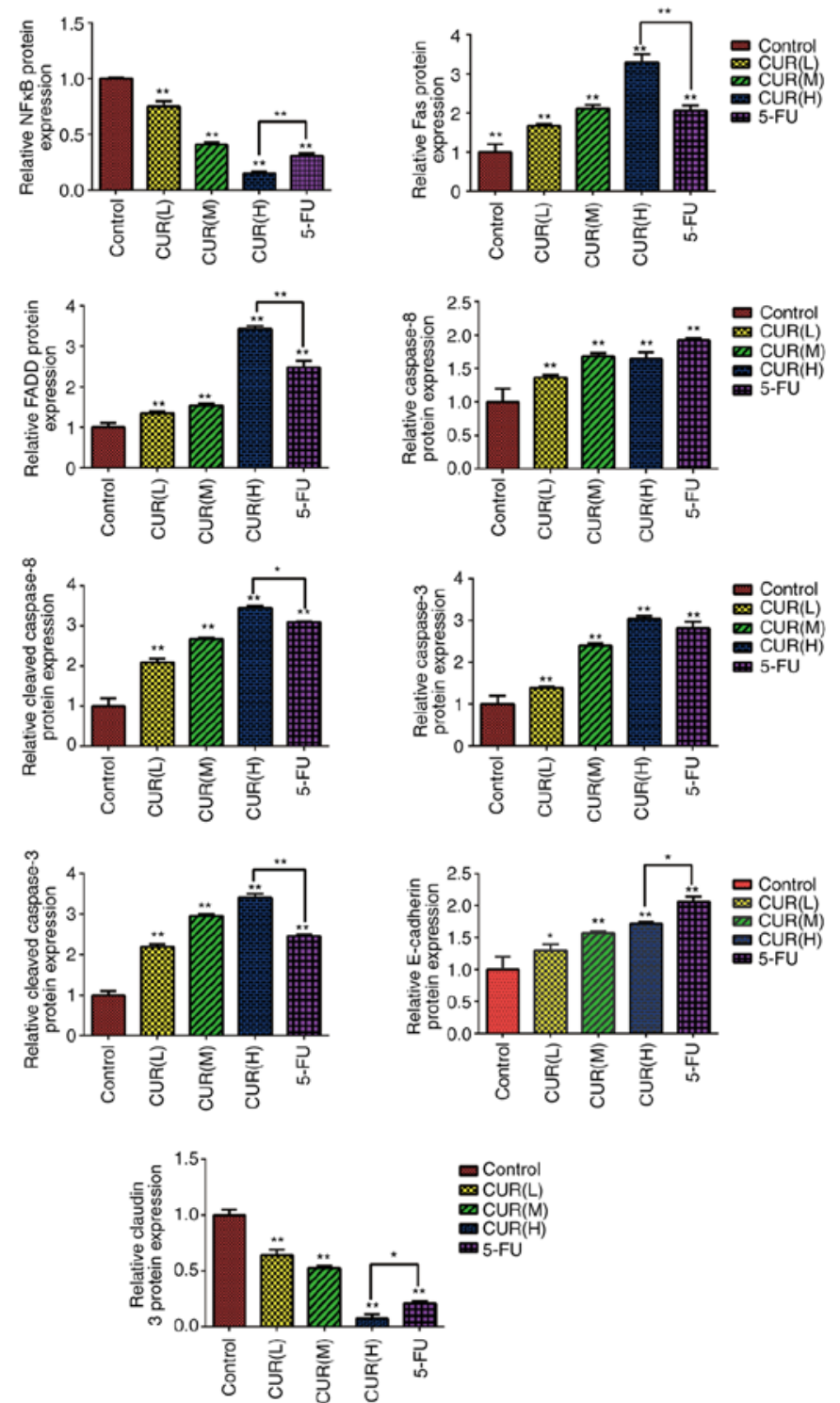

Figure 5. Curcumin affects the expression levels of Fas death receptor pathway-associated proteins/genes and tumor metastasis-associated proteins. (A) Following treatment with curcumin $(20 \mu \mathrm{M})$ and 5-FU $(500 \mu \mathrm{M})$, the expression levels of Fas death receptor signaling pathway-associated genes were assessed in HCT-116 cells using quantitative PCR analysis. (B) Following treatment with three different doses of curcumin (10, 20 and $30 \mu \mathrm{M})$ and 5-FU $(500 \mu \mathrm{M})$ for $24 \mathrm{~h}$, western blotting was used to determine the expression levels of various proteins (NF- $\mathrm{kB}$, Fas, FADD, caspase-8, cleaved-caspase-8, caspase-3, cleaved-caspase-3, E-cadherin and claudin-3) in HCT-116 cells. (C) Semi-quantification of the relative protein expression levels. Results are presented as the mean \pm standard error of the mean $(\mathrm{n} \geq 3)$. ${ }^{*} \mathrm{P}<0.05$ and ${ }^{* *} \mathrm{P}<0.01$ vs. control group. 5-FU, 5-fluorouracil; CUR(L), $10 \mu \mathrm{M}$ curcumin; CUR(M), $20 \mu \mathrm{M}$ curcumin; CUR(H), $30 \mu \mathrm{M}$ curcumin; FADD, Fas-associated protein with death domain; NF- $\kappa \mathrm{B}$, nuclear factor- $\kappa \mathrm{B}$.

curcumin could inhibit the differentiation of cells and decrease the numbers of stem-like cancer cells by affecting the whole cell population. Furthermore, the inhibitory effect of curcumin on the growth of HCT-116 cells was comparable to that of 5-FU. 
The basic process of cell life is supported by a complete cell cycle and generally develops in the order of $\mathrm{G}_{1}-\mathrm{S}-\mathrm{G}_{2}-\mathrm{M}$ phase. When certain factors impair the integrity of the cell DNA, cells cannot pass through the $\mathrm{G}_{1} / \mathrm{S}$ and $\mathrm{G}_{2} / \mathrm{M}$ detection points, which eventually inhibits cell proliferation and migration (38). Shehzad et al reported that curcumin may cause cell cycle arrest by decreasing the expression levels of certain genes to inhibit tumor cell proliferation (39). Flow cytometry demonstrated that curcumin triggered S-phase arrest in HCT-116 cells and inhibited cell proliferation in a dose-dependent manner. The results were consistent with the results of a previous study that demonstrated that 5-FU incorporates DNA double chains when it replicates during the $S$ phase of the cell cycle and leads to cell death $(32,40)$. Additionally, curcumin was able to achieve the effect of 5-FU treatment on S-phase arrest of HCT-116 cells.

Apoptosis is considered to be the key to an effective anticancer treatment regimen. In the present study, curcumin treatment induced apoptosis of HCT-116 cells. The morphological observation and flow cytometry data suggested that curcumin induced apoptosis of HCT-116 cells in a dose- and time-dependent manner, as did 5-FU treatment, and the regulatory ability of curcumin treatment in HCT-116 cells was comparable to that of 5-FU treatment. Therefore, curcumin inhibited the growth of HCT-116 cells by inducing apoptosis.

To the best of our knowledge, caspases modulate cell growth and apoptosis (41), and apoptosis can be promoted by caspase regulation. The caspase family is the initiator and the executor of programmed cell death in mammals. The caspase initiator is first activated by apoptosis signals, followed by activation of caspase effector molecules of the downstream cascade. Finally, a series of substrates in cells are specifically hydrolyzed, which leads to cell disintegration. Caspase-3 is the most important apoptotic effector molecule, and it is at the hub of each signaling pathway. Following the activation of caspase-3, cell death is inevitable (42). RT-qPCR and western blot analyses indicated that curcumin treatment markedly upregulated the expression levels of Fas in a dose-dependent manner, which activated the Fas death receptor signaling pathway and regulated FADD expression to activate caspase- 8 and caspase-3. Overexpression of caspase- 3 induced apoptosis in HCT-116 cells, which was consistent with other apoptosis-related experiments, such as the analysis of morphological changes and Annexin V-FITC/PI dual staining flow cytometry. Notably, curcumin treatment matched or even exceeded the effect of 5-FU treatment on the caspase expression levels in HCT-116 cells.

It is well known that invasion and metastasis are key biological characteristics of malignant tumors. Adhesion molecules play a crucial role in the occurrence, invasion and metastasis of malignant tumors. Tumor cells can accumulate in the target organ by penetrating through the blood vessel wall, thus activating tumor invasion (43). Transwell assays demonstrated that curcumin suppressed the migration and invasion of HCT-116 cells in a dose-dependent manner. Furthermore, in the present study, an artificial lung metastasis model was constructed using tail vein injection. The artificial metastasis model has the advantages of detecting tumor cell adhesion and the ability to pass through the blood vessel walls of target organs (44). Tail vein injection is mainly used to establish the tumor lung metastasis model (45). According to the characteristics of the artificial metastasis model, metastasis of HCT-116 cells to the lungs of mice was observed, but not to other tissues or organs. The results of the CFSE fluorescence labeling assay indicated that curcumin markedly inhibited HCT-116 cell aggregation and invasion of mouse lung tissues. The inhibitory effect of curcumin treatment was similar to that of 5-FU treatment.

$\mathrm{NF}-\kappa \mathrm{B}$ is one of the most important cell transcription factors. It is involved in the transcriptional regulation of numerous genes and is closely associated with the development of tumors (46). Overexpression of $\mathrm{NF}-\kappa \mathrm{B}$ activates the transcription of cyclin D1, which regulates the cell cycle and enhances cell proliferation $(32,47)$. Qazi et al $(17)$ revealed that inhibiting the activation of the NF- $\kappa \mathrm{B}$ signaling pathway can regulate related signaling pathways, inhibit inflammatory factors, activate apoptotic signals and promote cell apoptosis, thereby inhibiting tumor progression. A subsequent study (48) demonstrated that activation of the NF- $\kappa \mathrm{B}$ signaling pathway can block chemokines and induce EMT and invasion of tumor cells. Therefore, inhibition of NF- $\kappa \mathrm{B}$ can effectively inhibit tumor metastasis.

The tight junction is a vital membrane junction complex between adjacent cells, and claudin is the main structural protein (49). Abnormal protein expression of claudin has been reported in a variety of malignant tumors (15), and related studies on claudin-3 expression in $\mathrm{CRC}$ have been performed (50). MMP-9 can mediate the degradation of the extracellular matrix and provides suitable conditions for the infiltration and diffusion of tumor cells (16). Additionally, the expression of the intercellular adhesion factor E-cadherin is considered to be a marker of EMT (51). Overall, when investigating the possible molecular mechanism of cell metastasis, the zymography assay and western blotting demonstrated that curcumin treatment downregulated the expression levels of NF- $\kappa \mathrm{B}$, claudin-3 and MMP-9 in HCT-116 cells, and also upregulated the expression levels of E-cadherin in a dose-dependent manner.

Based on the observation of the present study that curcumin altered the expression levels of tumor metastasis-associated molecular targets, it was hypothesized that the possible molecular mechanism of action of curcumin involved the $\mathrm{NF}-\kappa \mathrm{B}$ signaling pathway, which could regulate MMP expression to induce EMT. Incidentally, this hypothesis regarding the possible molecular regulatory mechanism has been presented in a previous study (52). However, the conclusions regarding the mechanism of NF- $\kappa \mathrm{B}$ and EMT regulation have rarely been presented in previous studies on curcumin treatment in HCT-116 cells. Furthermore, the observation that the $\mathrm{NF}-\kappa \mathrm{B}$ signaling pathway can induce anti-apoptotic signaling pathways $(32,53)$ was confirmed in the present study. Shakibaei et al (32) reported that curcumin regulated $\mathrm{Bax}$ and $\mathrm{Bcl}-2$ to induce apoptosis in HCT-116 cells. However, in the present study, regarding the possible molecular mechanism of action of curcumin, it was hypothesized that NF- $\kappa \mathrm{B}$ inhibited the Fas signaling pathway to induce apoptosis. $\mathrm{NF}-\kappa \mathrm{B}$, Fas and E-cadherin regulate the proliferation, migration and invasion of CRC cells. Therefore, agents that downregulate the expression levels of NF- $\kappa \mathrm{B}$ and upregulate the expression levels of Fas and E-cadherin may be a possible strategy for inhibiting the progression of CRC.

In conclusion, the antitumor effects, including the effects on cell migration and proliferation, of curcumin on HCT-116 
cells were investigated. Curcumin did not only inhibit the proliferation and migration of HCT-116 cells, but also induced apoptosis. In terms of the possible molecular mechanism underlying these antitumor effects, curcumin likely suppressed the NF- $\mathrm{NB}$ signaling pathway to induce the activation of the Fas death receptor signaling pathway and inhibit EMT, through paracrine regulation of MMP-9 and cell tight junctions. Notably, the present study demonstrated that the inhibitory effect of curcumin on the HCT-116 cells was similar to that of 5-FU treatment in vitro. Most of the indicators were detected in vitro, and a single CRC cell line (HCT-116) was used in the present study. Another limitation was we did not use inhibitors against either Fas, caspase-8, or NF- $\kappa \mathrm{B}$, and did not investigate the expression of additional EMT markers, such as $\mathrm{N}$-cadherin and vimentin. Therefore, the present study only preliminarily indicated the effect of curcumin on EMT, and the NF- $\kappa \mathrm{B}$ signaling pathway is a possible molecular mechanism through which curcumin regulated the proliferation and migration of HCT-116 cells. In subsequent studies, the effects and the mechanism of curcumin treatment on CRC must be verified through the use of inhibitors, and the investigation of additional EMT markers in other CRC cell lines and in vivo.

\section{Acknowledgements}

Not applicable.

\section{Funding}

The present study was supported by the Science and Technology Project of Hubei Provincial Department of Education (grant no. D20162001).

\section{Availability of data and materials}

All data generated or analyzed during the present study are included in this published article.

\section{Authors' contributions}

LX performed the experiments, analyzed the data and drafted the manuscript. BH conducted western blotting experiments and flow cytometry. QL, DDH, WJL and RCL conducted the cell culture assay. GZ and QW designed the study, conceived the experiments, laid out the experimental scheme, edited and revised the paper. All the authors have read and approved the final version of the manuscript to be published.

\section{Ethics approval and consent to participate}

All animal protocols were approved by the Hubei University of Traditional Chinese Medicine Ethics Committee.

\section{Patient consent for publication}

Not applicable.

\section{Competing interests}

All the authors declare that they have no competing of interest.

\section{References}

1. Duan Y, Fang Z, Shi Z and Zhang L: Knockdown of lncRNA CCEPR suppresses colorectal cancer progression. Exp Ther Med 18: 3534-3542, 2019

2. Yu F, Zhou C, Zeng H, Liu Y and Li S: BMI1 activates WNT signaling in colon cancer by negatively regulating the WNT antagonist IDAX. Biochem Biophys Res Commun 496: 468-474, 2018.

3. Krijger ID, Mekenkamp LJ, Punt CJ and Nagtegaal LD: MicroRNAs in colorectal cancer metastasis. J Pathol 224: 438-447, 2011.

4. Bengmark $S$ and Hafström L: The natural history of primary and secondary malignant tumors of the liver. I. The prognosis for patients with hepatic metastases from colonic and rectal carcinoma by laparotomy. Cancer 23: 198-202, 1969.

5. Nordman IC, Iyer S, Joshua AM and Clarke SJ: Advances in the adjuvant treatment of colorectal cancer. ANZ J Surg 76: 373-380, 2006.

6. Apostolou P, Toloudi M, Kalliara I, Kipourou V, Tourna I and Papasotiriou I: Gene expression changes in colorectal cancer during metronomic chemotherapy and high-concentration drug administration. J Cancer Ther 6: 679-689, 2015.

7. Alfarouk KO: Tumor metabolism, cancer cell transporters, and microenvironmental resistance. J Enzyme Inhib Med Chem 31: 859-866, 2016.

8. Gupta SC, Patchva S and Aggarwal BB: Therapeutic roles of curcumin: lessons learned from clinical trials. AAPS J 15: 195-218, 2013.

9. Kuttan R, Bhanumathy P, Nirmala K and George MC: Potential anticancer activity of turmeric (Curcuma longa). Cancer Lett 29: 197-202, 1985.

10. Dai XZ, Yin HT, Sun LF, Hu X, Zhou C, Zhou Y, Zhang W, Huang XE and Li XC: Potential therapeutic efficacy of curcumin in liver cancer. Asian Pac J Cancer Prev 14: 3855-3859, 2013.

11. Merlin JLP: Biochemical characterization of caspase-12 in apoptosis and a way for its purification using fusion proteins. J Chosun Nat Sci 7: 103-112, 2014.

12. Dasmahaparea G, Almenara JA and Grant S: Flavopiridol and histone deacetylase inhibitors promote mitochondrial injury and cell death in human leukemia cells that overexpress Bcl-2. Mol Pharmacol 69: 288, 2006

13. Szarynska M, Olejniczak A, Wierzbicki P, Kobiela J, Laski D, Sledzinski Z, Adrych K, Guzek M and Kmiec Z: FasR and FasL in colorectal cancer. Int J Oncol 51: 975-986, 2017.

14. Sánchez-Tilló E, de Barrios O, Siles L, Cuatrecasas M, Castells A and Postigo A: $\beta$-catenin/TCF4 complex induces the epithelial-to-mesenchymal transition (EMT)-activator ZEB1 to regulate tumor invasiveness. Proc Natl Acad Sci USA 108: 19204-19209, 2011.

15. Karabulut M, Alis H, Bas K, Karabulut S, Afsar CU, Oguz H, Gunaldi M, Akarsu C, Kones O and Aykan NF: Clinical significance of serum claudin-1 and claudin-7 levels in patients with colorectal cancer. Mol Clin Oncol 3: 1255-1267, 2015.

16. Benedicto A, Romayor I and Arteta B: Role of liver ICAM-1 in metastasis. Oncol Lett 14: 3883-3892, 2017.

17. Qazi AK, Hussain A, Aga MA, Ali S, Taneja SC, Sharma PR, Saxena AK, Mondhe DM and Hamid A: Cell specific apoptosis by RLX is mediated by $\mathrm{NF} \kappa \mathrm{B}$ in human colon carcinoma HCT-116 cells. BMC Cell Biol 15: 36, 2014.

18. Gogly B, Groult N, Hornebeck W, Godeaua G and Pellata B: Collagen zymography as a sensitive and specific technique for the determination of subpicogram levels of interstitial collagenase. Anal Biochem 255: 211-216, 1998.

19. Hoefel D, Grooby WL, Monis PT, Andrews S and Saint CP: A comparative study of carboxyfluorescein diacetate and carboxyfluorescein diacetate succinimidyl ester as indicators of bacterial activity. J Microbiol Methods 52: 379-388, 2003.

20. Chidambaram M, Manavalan R and Kathiresan K: Nanotherapeutics to overcome conventional cancer chemotherapy limitations. J Pharm Pharm Sci 14: 67-77, 2011.

21. Ren M, Ye L, Hao X, Ren Z, Ren S, Xu K and Li J: Polysaccharides from Tricholoma matsutake and Lentinus edodes enhance 5-fluorouracil-mediated H22 cell growth inhibition. J Tradit Chin Med 34: 309-316, 2014.

22. Suttle AB, Ball HA, Molimard M, Hutson TE, Carpenter C, Rajagopalan D, Lin Y, Swann S, Amado R and Pandite L: Relationships between pazopanib exposure and clinical safety and efficacy in patients with advanced renal cell carcinoma. Br J Cancer 111: 1909-1916, 2014. 
23. Quispe-Sotol ET and Calaf GM: Effect of curcumin and paclitaxel on breast carcinogenesis. Int J Oncol 49: 2569-2577, 2016.

24. He B, Wei W, Liu J, Xu YD and Zhao G: Synergistic anticancer effect of curcumin and chemotherapy regimen FP in human gastric cancer MGC-803 cells. Oncol Lett 14: 3387-3394, 2017.

25. Vinod BS, Antony J, Nair HH, Puliyappadamba VT, Saikia M, Narayanan SS, Bevin A and Anto RJ: Mechanistic evaluation of the signaling events regulating curcumin-mediated chemosensitization of breast cancer cells to 5-fluorouracil. Cell Death Dis 4 e505, 2013

26. Aggarwal ML, Chacko KM and Kuruvilla BT: Systematic and comprehensive investigation of the toxicity of curcuminoid-essential oil complex: A bioavailable turmeric formulation. Mol Med Rep 13: 592-604, 2016.

27. Panahi Y, Saadat A, Beiraghdar F, Hosseini Nouzari SM Jalalian HR and Sahebkar A: Antioxidant effects of bioavailability-enhanced curcuminoids in patients with solid tumors: A randomized double-blind placebo-controlled trial. J Funct Foods 6: 615-622, 2014

28. Kunwar A, Barik A, Mishra B, Rathinasamy K, Pandey R and Priyadarsini KI: Quantitative cellular uptake, localization and cytotoxicity of curcumin in normal and tumor cells. Biochim Biophys Acta 1780: 673-679, 2008.

29. Sivanantham B, Sethuraman S and Krishnan UM: Combinatorial effects of curcumin with an anti-neoplastic agent on head and neck squamous cell carcinoma through the regulation of EGFR-ERK1/2 and apoptotic signaling pathways. ACS Comb 18 22-35, 2016

30. Arumuggam N, Bhowmick NA and Rupasinghe HP: A review: Phytochemicals targeting JAK/STAT signaling and IDO expression in cancer. Phytother Res 29: 805-817, 2015.

31. Kumar G, Mittal S, Sak K and Tuli HS: Molecular mechanisms underlying chemopreventive potential of curcumin: Current challenges and future perspectives. Life Sci 148: 313-328, 2016.

32. Shakibaei M, Mobasheri A, Lueders C, Busch F, Shayan P and Goel A: Curcumin enhances the effect of chemotherapy against colorectal cancer cells by inhibition of NF- $\kappa \mathrm{B}$ and Src protein kinase signaling pathways. PLoS One 8: e57218, 2013

33. Li YB, Gao JL, Zhong ZF, Hoi PM, Lee SM and Wang YT: Bisdemethoxycurcumin suppresses MCF-7 cells proliferation by inducing ROS accumulation and modulating senescence-related pathways. Pharmacol Rep 65: 700-709, 2013

34. Sun W, Liu DB, Li WW, Zhang LL, Long GX, Wang JF, Mei Q and Hu GQ: Interleukin-6 promotes the migration and invasion of nasopharyngeal carcinoma cell lines and upregulates the expression of MMP-2 and MMP-9. Int J Oncol 44: 1551-1560, 2014.

35. Kang J, Kim E, Kim W, Seong KM, Youn H, Kim JW, Kim J and Youn B: Rhamnetin and cirsiliol induce radiosensitization and inhibition of epithelial-mesenchymal transition (EMT) by miR-34a-mediated suppression of Notch-1 expression in non-small cell lung cancer cell lines. J Biol Chem 288 27343-27357, 2013.

36. Fu Z, Chen X, Guan S, Yan Y, Lin H and Hua ZC: Curcumin inhibits angiogenesis and improves defective hematopoiesis induced by tumor-derived VEGF in tumor model through modulating VEGF-VEGFR2 signaling pathway. Oncotarget 6 : 19469-19482, 2015.

37. Aaron JS, John O and Dino P: Multiple Actions of curcumin including anticancer, anti-inflammatory, antimicrobial and enhancement via cyclodextrin. J Cancer Ther 6: 257-272, 2015.
38. Siegel R, Desantis C, Virgo K, Stein K, Mariotto A, Smith T, Cooper D, Gansler T, Lerro C, Fedewa S, et al: Cancer treatment and survivorship statistics, 2012. CA Cancer J Clin 62: 220-241, 2012.

39. Shehzad A, Khan S, Shehzad O and Lee YS: Curcumin therapeutic promises and bioavailability in colorectal cancer. Drugs Today (Barc) 46: 523-532, 2010.

40. Harrison DE and Lerner CP: Most primitive hematopoietic stem cells are stimulated to cycle rapidly after treatment with 5-fluorouracil. Blood 78: 1237-1240, 1991.

41. Nicholson DW: Caspase structure, proteolytic substrates, and function during apoptotic cell death. Cell Death Differ 6: 1028-1042, 1999

42. Huang Q, Li F, Liu X, Li W, Shi W, Liu FF, O'Sullivan B, He Z, Peng Y, Tan AC, et al: Caspase 3-mediated stimulation of tumor cell repopulation during cancer radiotherapy. Nat Med 17: 860-866, 2011

43. Hyoudou K, Nishikawa M, Umeyama Y, Kobayashi Y, Yamashita $\mathrm{F}$ and Hashida $\mathrm{M}$ : Inhibition of metastatic tumor growth in mouse lung by repeated administration of polyethylene glycol-conjugated catalase: Quantitative analysis with firefly luciferase-expressing melanoma cells. Clin Cancer Res 10: 7685-7691, 2004.

44. Teicher BA (ed): Tumor models in cancer research. Springer Science \& Business Media, 2010.

45. Lorger M and Felding-Habermann B: Capturing changes in the brain microenvironment during initial steps of breast cancer brain metastasis. Am J Pathol 176: 2958-2971, 2010.

46. Hayden MS and Sankar G: NF- $\mathrm{BB}$, the first quarter-century: Remarkable progress and outstanding questions. Genes Dev 26: 203-234, 2012

47. Meng Q, Zhi T, Chao Y, Nie E, Xu X, Shi Q, Hua L, Wang L, Zhan W, Wang Y, et al: Bex2 controls proliferation of human glioblastoma cells through NF- $\mathrm{B}$ signaling pathway. J Mol Neurosci 53: 262-270, 2014

48. Zheng Y, Miu Y, Yang X, Yang X, and Zhu M: CCR7 mediates TGF- $\beta 1$-induced human malignant glioma invasion, migration, and epithelial-mesenchymal transition by activating MMP2/9 through the nuclear factor kappaB signaling pathway. DNA Cell Biol 36: 853-861, 2017.

49. Wang $\mathrm{H}$ and Yang $\mathrm{X}$ : The expression patterns of tight junction protein claudin-1, -3 , and -4 in human gastric neoplasms and adjacent non-neoplastic tissues. Int J Clin Exp Patho 8: 881-887, 2015.

50. Oliveira SS and Morgado-Díaz JA: Claudins: Multifunctional players in epithelial tight junctions and their role in cancer. Cell Mol Life Sci 64: 17-28, 2007.

51. Guarino M, Rubino B and Ballabio G: The role of epithelial-mesenchymal transition in cancer pathology. Pathology 39: 305-318, 2007.

52. Downey C, Craig DH and Basson MD: Isoform-specific modulation of pressure-stimulated cancer cell proliferation and adhesion by $\alpha$-actinin. Am J Surg 202: 520-523, 2011.

53. Shant J, Cheng K, Marasa BS, Wang JY and Raufman JP: Akt-dependent NF-kappaB activation is required for bile acids to rescue colon cancer cells from stress-induced apoptosis. Exp Cell Res 315: 432-450, 2009.

This work is licensed under a Creative Commons

Attribution-NonCommercial-NoDerivatives 4.0 International (CC BY-NC-ND 4.0) License. 